\title{
Next-generation sequencing refines the genetic architecture of Greek GnRH-deficient patients
}

\author{
M I Stamou 1,2,3, P Varnavas², L Plummer', V Koika² and N A Georgopoulos ${ }^{2}$ \\ ${ }^{1}$ Harvard Reproductive Sciences Center, Massachusetts General Hospital, Boston, Massachusetts, USA \\ 2Department of Obstetrics and Gynecology, Division of Reproductive Endocrinology, University Regional Hospital of Patras, Rio, Greece \\ ${ }^{3}$ Mount Auburn Hospital, Harvard Medical School Teaching Hospital, Cambridge, Massachusetts, USA
}

Correspondence should be addressed to N A Georgopoulos: neoklisgeorgo@gmail.com

\begin{abstract}
Isolated gonadotropin-releasing hormone (GnRH) deficiency (IGD) is a rare disease with a wide spectrum of reproductive and non-reproductive clinical characteristics. Apart from the phenotypic heterogeneity, IGD is also highly genetically heterogeneous with $>35$ genes implicated in the disease. Despite this genetic heterogeneity, genetic enrichment in specific subpopulations has been described. We have previously described low prevalence of genetic variation in the Greek IGD cohort discovered with utilization of Sanger sequencing in 14 known IGD genes. Here, we describe the expansion of genetic screening in the largest IGD Greek cohort that has ever been studied with the usage of whole-exome sequencing, searching for rare sequencing variants (RSVs) in 37 known IGD genes. Even though Sanger sequencing detected genetic variation in 21/81 IGD patients in 7/14 IGD genes without any evidence of oligogenicity, whole exome sequencing (WES) revealed that 27/87 IGD patients carried a rare genetic change in a total of 15 genes with 4 IGD cases being oligogenic. Our findings suggest that next-generation sequencing (NGS) techniques can discover previously undetected variation, making them the standardized method for screening patients with rare and/or more common disorders.
\end{abstract}

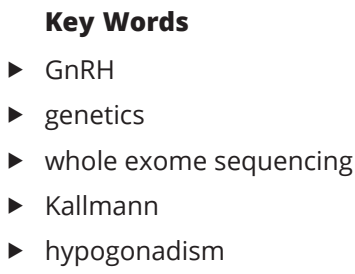

Endocrine Connections (2019) 8, 468-480

\section{Introduction}

Isolated gonadotropin-releasing hormone (GnRH) deficiency (IGD) is a rare disease with a wide spectrum of reproductive and non-reproductive clinical characteristics. Apart from the phenotypic heterogeneity, IGD is also a genetically enriched disease with $\sim 37$ genes being implicated in its pathophysiology $(2,3)$. The genetic basis of disorders of sex development has been previously studied with a prevalence of genetic changes $\sim 45 \%(4,5)$, whereas in the genetically heterogeneous IGD only $~ 50 \%$ of patients have a genetic mutation that is identifiable $(2,6)$.

Mutations in genes that disrupt the neurodevelopmental pathway of GnRH, that is the development and migration of GnRH neurons cause Kallmann Syndrome (KS), and such genes include ANOS1 - Anosmin 1, previously known as KAL1 - Kallmann 1,
NSMF - NMDA receptor synaptonuclear signaling and neuronal migration factor, FGFR1 - fibroblast growth factor receptor 1, FGF8 - fibroblast growth factor 8, FGF17 - fibroblast growth factor 17, IL17RD - interleukin 17 receptor D, PROK2 - prokineticin 2, PROKR2 - prokineticin receptor 2, HS6ST1 - heparin sulfate 6 O sulfutransferase, CHD7 - chromodomain helicase DNA-binding protein 7, WDR11 - WD repeat-containing protein 11, SEMA3A semaphorin 3A, TUBB3 - tubulin beta 3, SOX10 - SRY box 10 and many more $(7,8)$.

On the other hand, genes that interfere with the neuroendocrine physiology of the normal secretion of GnRH (GNRH1 - GnRH 1, KISS1 - kisspeptin 1, KISS1R (GPR54) - kisspeptin 1 receptor, TAC3 - tachykinin 3, TACR3 - tachykinin receptor 3, LEP - leptin, $L E P R$ - leptin receptor) or its action on the pituitary 
(GNRHR - GnRH receptor), cause normosmic idiopathic hypogonadotropic hypogonadism (nIHH) $(7,9)$. The majority of the genes are considered 'overlap genes' (i.e. the ones that are found to be disrupted in both $\mathrm{KS}$ and nIHH patients) and these (so far) include NSMF, FGFR1, FGF8, FGF17, IL17RD, PROK2, PROKR2, HS6ST1, CHD7, WDR11 and SEMA3A. Presumably, these genes may have multiple roles in GnRH biology including both $\mathrm{GnRH}$ neuronal migration and their secretory function, although for many genes this theory remains to be examined (8).

Different strategies have been utilized for gene discovery including analysis of chromosomal rearrangements, sequencing of syndromic cases, candidate gene approach and studies of endogamous families/populations (2). Despite the major genetic and phenotypic heterogeneity of IGD, genetic enrichment has been identified in specific ethnic sub-populations and several studies have estimated the prevalence of IGD genes in specific ethnic populations $(10,11,12,13)$. Studies of endogamous pedigrees of Turkish, Kurdish and Bedouin origin have identified important IGD players including the genes of KISS1 and KISS1R, TAC3 and its receptor TACR3 as well as recently FEZF1 $(14,15,16,17)$. In addition to these pedigree-based analyses, studies in isolated patient populations have shown significant enrichment for rare loss-of-function (LoF) mutations in known genes (18). For example, the frequency of rare sequence variants (RSVs) in PROKR2 is far higher in the geographically limited Maghrebian (North African) KS population than in European KS patients and similarly (11) and 77\% of familial nIHH cases of Turkish origin have been shown to be enriched for a subset of neuroendocrine IGD genes including GnRH receptor gene - GNRHR, TAC3, TACR3, KISS1 and KISS1R (19). Thus, it seems that geographically delimitated populations are enriched for specific genes that arise in the backbone of shared inherited haplotypes.

We have previously described an enrichment of the normosmic phenotypic variation of the IGD phenotype in the Greek patients with IGD as well as low prevalence of genetic variation in the Greek IGD cohort and absence of oligogenicity, highlighting the possible presence of a yet unidentified genetic cause that contributes to the expression of the IGD phenotype in this ethnic subpopulation (1). Given that next-generation sequencing (NGS) has emerged a huge number of genes and variation in multiple diseases and disorders, we utilized whole exome sequencing (WES) to examine if application of NGS has any effect on the prevalence of genetic variation and oligogenicity identified in the cohort studied. Thus, in our analysis we expanded the cohort of Greek patients with
IGD to 87 probands and utilized the strength of this large cohort of IGD patients of Greek origin to investigate the genetic basis of IGD and uncover the prevalence of genetic variation in major genetic players of IGD. For the analysis we performed detailed phenotyping and genotyping using both Sanger and whole exome sequencing in order to (i) describe the reproductive and non-reproductive features of Greek patients with IGD; (ii) estimate the prevalence of RSVs in 37 IGD genes after utilization of WES (and compare it with 'traditional' screening using Sanger sequencing in 14 known genes) and finally (iii) estimate the prevalence of oligogenicity in the Greek IGD cohort by detecting genetic variants in 'modifier' genes.

\section{Materials and methods}

\section{Subjects}

Inclusion criteria for IGD patients have been described before (1) and consisted of (i) clinical diagnosis of IGD: this was defined as delay or absence of pubertal development by the age of 18 years and low sex steroid levels in the presence of low or normal gonadotropins; (ii) normal other pituitary function and (iii) no neuroanatomic or functional cause of hypogonadotropic hypogonadism. A total of 87 probands participated in this study. Forty-five patients were seen in the Department of Reproductive Endocrinology of the University of Patras and 42 were referred from collaborating physicians acknowledged at the end of this article. DNA samples and permission from the patients were obtained in the Division of Reproductive Endocrinology of the University of Patras as well as by collaborative providers (please refer to acknowledgements). All participants remained anonymous. The study was approved by Institutional Review Board of Patras Medical School.

\section{Phenotyping}

For phenotypic analysis, detailed clinical evaluation was performed in the patients seen in the University of Patras. Detailed medical history from the proband and the extended family was obtained to determine the pattern of inheritance and the degree of penetrance of any identified genetic changes. Additionally, subjects completed dedicated patient questionnaires, underwent detailed laboratory work-up, renal imaging and GnRH stimulation tests. The olfactory function was assessed based on the University of Pennsylvania Smell Identification Test (UPSIT). In few cases with a medical and/or family history

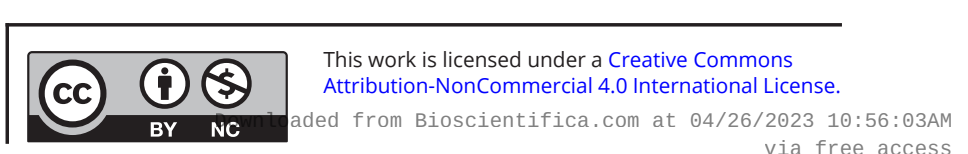


of psychiatric disorders, detailed psychiatric evaluation was performed using the Hamilton scale for depression and anxiety as well as the Hospital Anxiety and Depression Score (HADS) (20). For patients referred from collaborative physicians, the outside physician records were used for phenotypic analysis. To ascertain the enrichment of specific phenotypic features in each patient group, the proportion of probands exhibiting the phenotype was compared between those who were diagnosed with KS vs those who were diagnosed with nIHH. Therefore, a Fisher exact $2 \times 2$ test was used for each qualitative phenotype. A $P$ value $<.05$ was considered statistically significant.

\section{Sanger sequencing}

Eighty-one probands were subjected to Sanger sequencing for 14 well-validated genes as described before (1). Those genes fulfilled the majority of the validated genetic criteria including genetic burden, protein interactions, biochemical function, tissue expression, model systems and rescue and gene burden analysis (2). Genomic DNA was obtained from peripheral blood samples by standard phenol-chloroform extraction. Exonic and proximal intronic ( $\leq 15 \mathrm{bp}$ from splice sites) DNA sequences of the genes were amplified by PCR and determined by direct sequencing: ANOS1 (OMIM 308700), GNRH1 (OMIM 152760), GNRHR (OMIM 138850), KISS1R (OMIM 604161), KISS1 (OMIM 603286), CHD7 (OMIM 608892), NSMF (OMIM 608137), FGF8 (OMIM 600483), FGFR1 (OMIM 136350), PROK2 (OMIM 607002), PROKR2 (OMIM 607212), HS6ST1 (OMIM 1 604846), TAC3 (OMIM 162330) and TACR3 (OMIM 162332). The PCR primers and amplification conditions for each gene have been previously published $(21,22)$.

\section{Whole exome sequencing}

Eight-seven probands and 89 affected and unaffected family members (with a total number of 176 individuals) underwent WES. WES was performed at the Broad Institute Sequencing Platform. RSVs were sought in the following 37 known IGD genes: AXL (OMIM ID: 109135), CHD7 (OMIM 608892), DUSP6 (OMIM ID: 602748 ), FEZF1 (OMIM ID: 613301), FGF17 (OMIM ID: 603725), FGF8 (OMIM 600483), FGFR1 (OMIM 136350), FLRT3 (OMIM ID: 604808), GNRH1 (OMIM 152760), GNRHR (OMIM 138850), HS6ST1 (OMIM 1604846), IL17RD (OMIM ID: 606807), ANOS1 (OMIM 308700), KISS1 (OMIM 603286), KISS1R (OMIM 604161), LEP (OMIM ID: 164160), LEPR (OMIM ID: 601007), NSMF (OMIM 608137), OTUD4 (OMIM ID: 611744),
PCSK1 (OMIM ID: 162150), PNPLA6 (OMIM ID: 603197), POLR3A (OMIM ID: 614258), POLR3B (OMIM ID: 614366), PROKR2 (OMIM 607212), PROK2 (OMIM 607002), RNF216 (OMIM ID: 609948), SEMA3A (OMIM ID: 603961), SEMA3E (OMIM ID: 608166), SOX10 (OMIM ID: 602229), SOX2 (OMIM ID: 184429), SPRY4 (OMIM ID: 607984), STUB1 (OMIM ID: 607207), TAC3 (OMIM 162330), TACR3 (OMIM 162332), WDR11 (OMIM ID: 606417), KL (OMIM ID: 604824) and DMXL2 (OMIM ID: 612186).

A $R S V$ was defined as a variant (i) affecting splice junctions within $10 \mathrm{bp}$ of coding sequence or a proteinaltering/protein-truncating non-synonymous variant and (ii) present in $<1 \%$ of the non-Finnish European population of the Exome Aggregation Consortium (ExAC) (Cambridge, MA, USA; http://exac.broadinstitute.org). Since no control cohorts of Greek origin are publicly available, an association test was performed for each of the RSVs detected, utilizing control sub-cohorts consisting of healthy individuals of European ancestry. To validate the accuracy of the use of such control cohort principal component analysis (PCA) data provided from the Reproductive Endocrine Unit of Massachusetts General Hospital in 12 IGD patients of Greek origin who underwent SNP-chip-sequencing was compared to multi-ethnic cohort data. Importantly, the patients of Greek origin clustered within European cohorts (data not shown).

\section{Validation of detected RSVs}

Given the accelerating discovery of rare genetic variation, several clear guidelines should be applied in order to determine a discovered genetic variant as causative, potential causative or not. Based on the recently published guidelines by MacArthur et al. (23) we tried to determine if the detected RSVs met the criteria for confidence in pathogenicity. As proposed by McArthur et al., the functional validation for all detected RSVs can be divided into three different categories: genetic, informative and experimental.

\section{Genetic validation}

To assess if a RSV is rare or not, the cut-off of MAF $<1 \%$ in non-Finnish European was utilized. When an RSV was detected in a familial case, segregation analysis was performed among family members.

\section{Informatic validation}

To assess for informatic validation of a detected RSV, we examined if the site of the variant displayed evolutionary

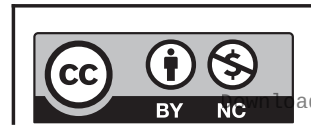

This work is licensed under a Creative Commons Attribution-NonCommercial 4.0 International License. ded from Bioscientifica.com at 04/26/2023 10:56:03AM via free access 
conservation consistent with deleterious effects of genomic changes at that location. To test for conservation, we utilized the publicly available database of genome.ucsc.edu that lists detailed conservation across multiple species including rhesus, mouse, dog, elephant, chicken, X_tropicalis, zebrafish and lamprey. A RSV occurring in a highly conserved region was considered to be of a high impact (24).

Several of the variants discovered have already undergone experimental validation including evidence of how the RSV alters the levels, splicing or normal biochemical function of the product of the affected gene in patient's cells or in vitro, evidence or phenotype recapitulation and rescue $(25,26,27)$. We also utilized bioinformatic prediction programs to predict the RSVs effect on the protein function in silico. For example, if a variant is found at a location within the protein predicted to cause functional disruption such as enzyme active site, proteinbinding region etc., it is more likely to have a functional effect on the protein level, and thus, be damaging.

The functional effect of the RSVs was analyzed based on the nature of the genomic change. In particular, high-impact variants included frameshift, nonsense and essential splice site RSVs and were considered pathogenic. Missense RSVs were considered of moderate impact and their functional effect was based on either previous functional studies or analysis based on bioinformatic prediction programs. The functional effect of such RSVs was tested using 4 prediction programs including Polyphen2 (28), SIFT (29), Pathner and FatHMM (30) and RSVs were characterized based on them as benign, likely benign, likely deleterious and deleterious. Finally, low impact RSVs included synonymous and extended splice site RSVs. Since in silico functional analysis can only provide with supporting evidence of pathogenicity, a thorough evaluation of the detected variants was undertaken based on the recently published criteria by the American College of Medical Genetics and the discovered RSVs were classified as pathogenic, likely pathogenic, benign, likely benign and of uncertain significance (31).

\section{Multiplex-ligation-dependent-probe amplification (MLPA) analysis}

It is known that ANOS1 genetic changes are exclusively identified in patients with KS, the majority of which display additional features such as renal agenesis or synkinesia $(32,33)$. As published before (1), apart from the analysis of coding RSVs, we searched for the presence of intergenic ANOS1 deletions and/or duplication in a subset of Greek patients who met the following criteria: (i) KS phenotype; (ii) negative for ANOS1 RSVs and (iii) expressing a non-reproductive phenotype consistent with ANOS1 mutations, such as synkinesia or unilateral renal agenesis (URA) (32). Gene dosage analysis was performed using the SALSA MLPA kit P132 Kallmann-1 (MRC Holland, Amsterdam, Netherlands) designed to detect exonic deletions/duplications across the entire coding region of ANOS1 gene.

\section{Results}

\section{Phenotyping of the IGD patients of Greek origin}

\section{Male-to-female ratio}

In this study, we expanded our analysis to 87 Greek patients who met the inclusion criteria for this study. The cohort consisted of 58 male and 29 female probands. A total of 57 probands were classified as nIHH, while 30 probands were diagnosed with KS. KS was strikingly predominant in men with a 5:1 male-to-female ratio (25 males and 5 females) compared to a modest 3:2 maleto-female ratio in nIHH (33 males and 24 females). The male predominance in the KS phenotype compared to the nIHH variant was found to be statistically significant with a $P$ value of 0.0183 .

\section{Reproductive and non-reproductive features}

Patients were phenotyped in detail for both reproductive and non-reproductive features. No statistically significant difference was found between the groups of KS and nIHH with regard to cryptorchidism or microphallus. A variety of non-reproductive features were detected including ichthyosis, URA, synkinesia, primary hypothyroidism, neurosensory hearing loss, osteopenia/ osteoporosis, congenital heart defects including coarctation of the aorta and ventricular septal defect (VDS), hematologic/immune disorders such as G6PD and IgA deficiency, cleft lip and palate, obesity and strabismus.

Of the assessed phenotypes, URA and synkinesia (S) were statistically enriched in KS, as shown in Table 1. Interestingly, the neuropsychiatric evaluation revealed depression in four IGD cases as well as few additional psychiatric disorders including psychotic syndrome and paranoid schizophrenia in a small subset of the IGD patients.

\section{Patterns of inheritance}

The vast majority of the cases assembled were found to be sporadic $(71 / 87)$ with the rest being familial, displaying different patterns of inheritance including X-linked (2/87),

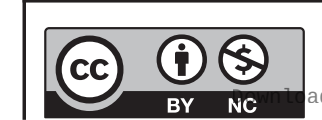


Table 1 Reproductive and non- reproductive features in the IGD.

\begin{tabular}{|c|c|c|c|}
\hline Clinical features & $\begin{array}{c}\mathbf{K S}(N=24 \\
\text { males, } \boldsymbol{N}=19)\end{array}$ & $\begin{array}{l}\text { nIHH }(N=29, \\
\text { males, } \boldsymbol{N}=14)\end{array}$ & $P$ value \\
\hline Cryptorchidism & $7 / 24,7 / 19$ & $5 / 29,5 / 14$ & 1 \\
\hline Microphallus & $6 / 24,6 / 19$ & $3 / 29$ & 0.6982 \\
\hline URA* & $6 / 24$ & $1 / 29$ & 0.0377 \\
\hline Synkinesia* & $6 / 24$ & $0 / 29$ & 0.0059 \\
\hline $\mathrm{CL} / \mathrm{CP}$ & $2 / 24$ & $1 / 29$ & 0.5841 \\
\hline Strabismus & $1 / 24$ & $0 / 29$ & 0.4528 \\
\hline $\begin{array}{l}\text { Primary } \\
\text { hypothyroidism }\end{array}$ & $2 / 24$ & $5 / 29$ & 0.6173 \\
\hline Icthyosis & $2 / 24$ & $0 / 29$ & 0.2003 \\
\hline Obesity & $2 / 24$ & $1 / 29$ & 0.5841 \\
\hline $\begin{array}{l}\text { Congenital heart } \\
\text { disease }\end{array}$ & $0 / 24$ & $1 / 29$ & 1 \\
\hline $\begin{array}{l}\text { Hematologic } \\
\text { disorder }\end{array}$ & $0 / 24$ & $2 / 29$ & 0.4949 \\
\hline Hearing loss & $0 / 24$ & $1 / 29$ & 1 \\
\hline Osteoporosis & $2 / 24$ & $6 / 29$ & 0.2688 \\
\hline Depression & $2 / 24$ & $2 / 29$ & 1 \\
\hline $\begin{array}{l}\text { Other psychiatric } \\
\text { disorders }\end{array}$ & $1 / 24$ & $2 / 29$ & 1 \\
\hline
\end{tabular}

Table 1 shows the reproductive and non-reproductive features of a subset of patients that presented to the Reproductive Endocrine Clinic of the University of Patras. The table shows the number of probands with KS and $\mathrm{nIHH}$ that displayed the different features and in parentheses is written the percentage of them displaying the characteristics. Asterisk (*) indicates features with statistically significant differences. $\mathrm{CL} / \mathrm{CP}$, cleft lip/cleft palate; congenital heart defect, coarctation of the aorta and ventricular septal defect (VSD); hematologic disorders, G6PD and IgA deficiency; other psychiatric disorders, psychotic syndrome and paranoid schizophrenia; URA, unilateral renal agenesis.

autosomal recessive (5/87) and autosomal dominant (11/87) mode of inheritance. A representative sample of a sample of IGD familial cases is shown in Fig. 1.

\section{Genotyping of IGD Greek patients}

\section{Prevalence of detected RSV in IGD genes using Sanger sequencing}

We have previously discovered genetic changes in IGD genes in 21/81 probands of Greek origin with the usage of Sanger sequencing in 14 known genes. RSVs were detected in 7/14 genes including CHD7, ANOS1, GNRHR, FGFR1, PROKR2, TACR3 and KISS1R. As shown in Fig. 2, the gene with the highest prevalence was $\mathrm{CHD7}$, as four RSVs were detected in CHD7 in six different IGD patients. Sanger sequencing detected two RSVs in ANOS1 (one nonsense and one missense RSV), whereas MLPA discovered two ANOS1 deletions in patients with KS and other nonreproductive features such as renal agenesis, synkinesia and icthyosis, making it the second most commonly genetically changed gene in the Greek IGD cohort. GNRHR was also found to carry RSVs in 4/81 IGD patients, who were all diagnosed with nIHH. PROKR2 and FGFR1 RSVs were also detected in $3 / 81$ and $2 / 81$ probands respectively, whereas only one patient in our cohort was found to carry an RSV in TACR3 and KISS1R.

\section{Estimating oligogenicity with Sanger sequencing}

Even though a large number of IGD genes was screened with Sanger sequencing, no oligogenic cases were detected in contrast to previous studies (34) that usually detect oligogenicity in $\sim 2.5-10 \%$ of the IGD population.

\section{Prevalence of detected RSV in IGD genes using WES}

The lack of genetic variation in a large number of IGD patients $(60 / 81)$ of the cohort analyzed as well as the lack of oligogenicity could reflect the presence of a yet unidentified genetic cause underlying the Greek cohort of IGD. To optimize the detection of RSVs in all genes that are implicated in the disease and test for oligogenicity in the cohort, we performed WES in all 81 patients that have undergone Sanger sequencing as well as six more IGD probands that were enrolled more recently in our study. We performed WES in both affected and unaffected family members (a total number of 176 individuals were screened). All RSVs discovered via WES were confirmed with Sanger sequencing and ten more rare variants were discovered in eight additional genes including DMXL2, SOX2, KL, POLR3A, POLR3B, PNPLA6, SEMA3A and $R N F 216$. The number of subjects carrying RSVs in those genes is shown in Fig. 3. Thirty-one genetic changes were found in 27 subjects. Even though eight more genes were found to be implicated in the genetic characterization of the IGD cohort, there was no statistically significant difference in the prevalence of genetic detection after WES was performed (21/81 vs $27 / 87, P$ value, 0.49$)$.

We were able to detect five pathogenic genetic changes including intergenic deletions in the gene of ANOS1, a frameshift RSV in the gene of CHD7 and two missense RSVs in GNRHR. One frameshift RSV was detected in PNAPL6 and two SOX2 RSVs that were predicted to be deleterious/damaging in all prediction programs. Ten of the RSVs were likely deleterious based on the in silico analysis and ten RSVs were predicted to be benign or likely benign. A summary of the detected variation with the MAF in non-Finnish Europeans is shown in Table 2.

\section{Estimating oligogenicity after WES}

After performing WES, four cases of oligogenicity were detected including (i) a KS male with two heterozygous RSVs in $K L$ c.860G >A p.R287H and POLR3A c.3734G>A p.R1245Q;

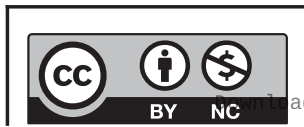


Pedigree A

Pedigree B

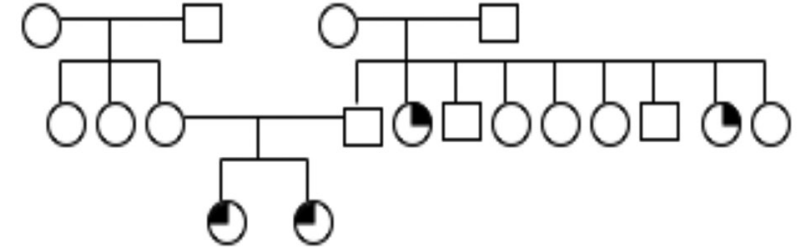

Pedigree C
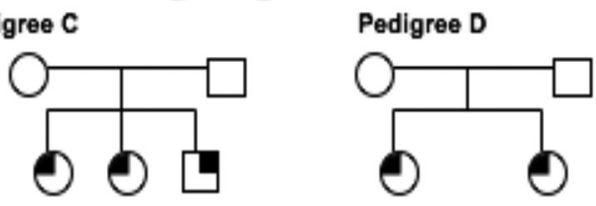

Pedigree G

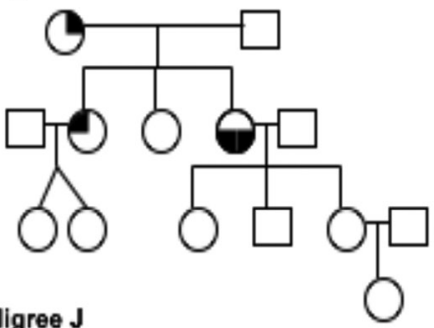

Pedigree J

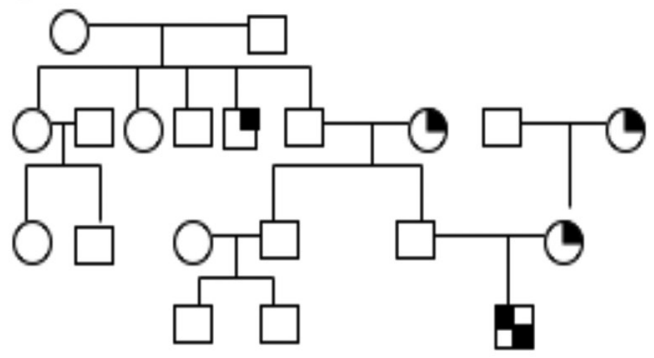

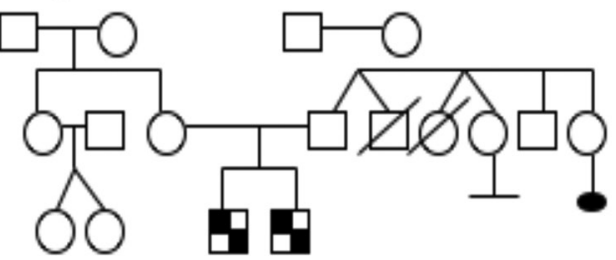

Pedigree E
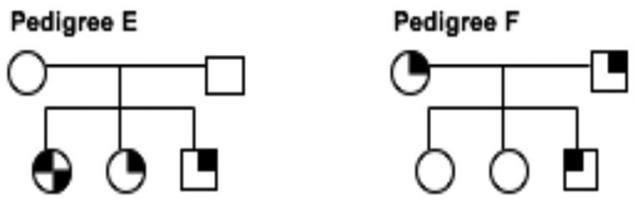

Pedigree $\mathrm{H}$

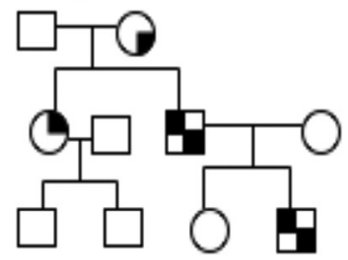

Pedigree I

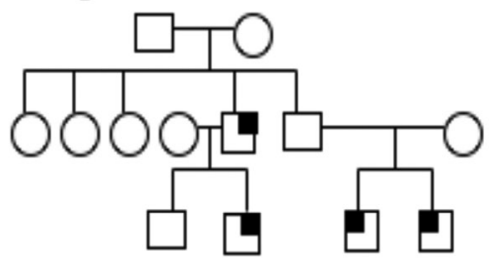

Pedigree K

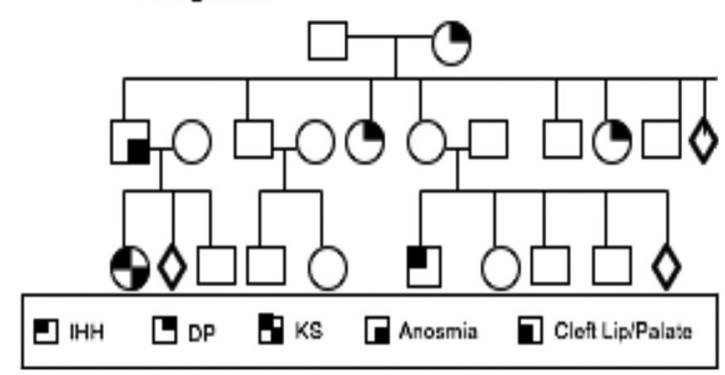

Figure 1

Different examples of familial cases of the Greek cohort. Both nIHH and KS are inherited with various pattern of inheritance: $\mathrm{X}$-linked (Pedigree B), autosomal recessive (Pedigrees C, D and E) and autosomal dominant with incomplete penetrance and variable expressivity (Pedigrees A, F, G, H, I, J and K). Of note, IGD was inherited with sporadic pattern of inheritance in most cases.

(ii) a KS male patient with heterozygous RSVs in DMXL2 c.3104C $>$ G p.P1035R and PNPLA6 c.851_859delinsACCGTGT p.S284YfsX56, as well as a possible deletion of ANOS1 exon 1-Xp22.31; (iii) a KS male with RSVs in the genes of SPRY4 c.46G>A p.V16I and SEMA3A c. $1457 \mathrm{C}>\mathrm{T}$ p.P486L and finally (iv) a nIHH female patient who carried two heterozygous RSVs in PROKR2 c.1069C $>\mathrm{T}$ p.R357W and RNF216 c.106G $>\mathrm{A}$ p.D36N. Oligogenicity in the IGD Greek cohort was found in 4 out of 87 probands. Importantly, even in oligogenic cases, the RSVs were found to be inherited with incomplete penetrance, highlighting the presence of possible additional genetic or epigenetic variations contributing to the expression of the phenotypes in those cases. A summary of the oligogenic cases is shown in Supplementary Figs 6, 8 and 9 (see section on supplementary data given at the end of this article).

\section{Validation of detected RSVs}

\section{Genetic validation}

Due to small power of our studied cohort, gene burden testing (i.e. if a gene is significantly enriched in cases compared to controls) could not be determined. The segregation of the detected variation was examined via Sanger sequencing as shown in Supplementary Figs 1, 2, $3,4,5,6,7,8$ and 9 .

\section{Informatic validation}

We tested the conservation among different species and all the RSVs detected in the Greek IGD cohort occurred in highly conserved genomic regions.

Some of the variants discovered have already undergone experimental validation including evidence of how the RSV alters the levels, splicing or normal

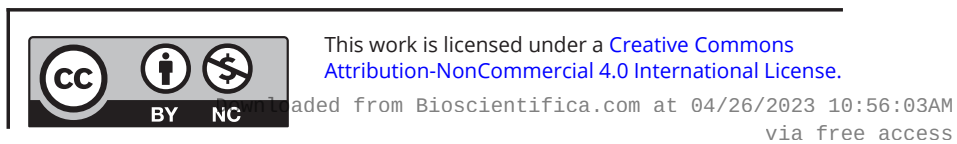




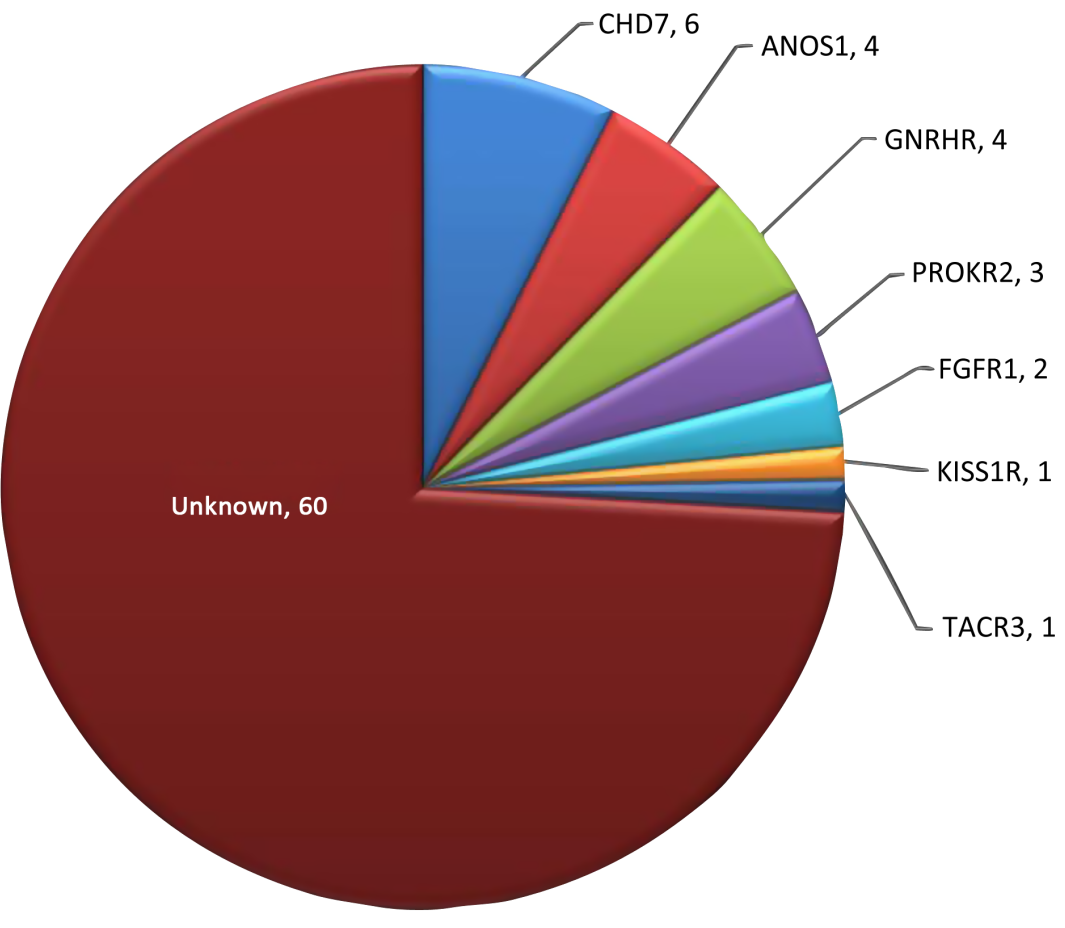

$\square$ CHD7 $\square$ ANOS1 $\square$ GNRHR $\square$ PROKR2 घFGFR1 घKISS1R घTACR3 घUnknown

\section{Figure 2}

The genes positive for rare sequence variants (RSVs) detected with Sanger sequencing in 81 IGD patients as well as the number of probands carrying them. RSVs were detected in the following genes: CHD7, ANOS1, GNRHR, PROKR2, FGFR1, KISS1R and TACR3. biochemical function of the product of the affected gene in patient's cells or in vitro, evidence or phenotype recapitulation and rescue $(25,26,27)$. The in silico functional validation of the detected RSVs is shown in Table 3. Of note, high-impact variants including frameshift, nonsense and slice site could not be evaluated by utilizing bioinformatics as they are considered deleterious a priori. As in silico validation is only one of the criteria that supports pathogenicity, we performed a detailed analysis of all detected RSVs and were able to categorize them as pathogenic, likely pathogenic, likely benign, benign and of unknown significance based on the ACMG criteria (see Table 3). The presence of a several variants of unknown significance among the detected variation can be attributed mostly to the lack of in vitro functional studies, lack of parental DNA that prevents testing for de novo variants and the oligogenic nature of the disease we study.

\section{Discussion}

Throughout the years of investigation, different techniques have been used to discover novel genes in IGD, such as structural defects, including contiguous gene deletion syndromes or copy number variations, syndromic cases, protein-protein interactions and endogamous pedigrees. Interestingly, specific subpopulations have been found to be enriched for particular genes that cause the disease. In our study, we attempted to describe the genetic background of a large cohort of IGD patients of Greek origin with the utilization of NGS. Even though studies of population isolated have led to novel gene discovery, the recruitment area of our cohort was nationwide, making this cohort the largest IGD cohort of Greek origin ever studied. We performed detailed phenotypic and genotypic analysis in 176 individuals, including 87 probands with $\mathrm{KS}$ and $\mathrm{nIHH}$ as well as 89 additional affected and unaffected family members.

\section{Phenotypic analysis}

Similar to our prior analysis of the 81 probands, our cohort was represented by a large number of nIHH patients compared to patients with KS, suggestive of a phenotypic enrichment of the normosmic feature, even though evaluation of the olfactory function of a subset of nIHH patients was based only on data given by our referring collaborators. Previous reports of ethnically mixed IGD patients report an almost equal ratio of KS and nIHH phenotypes (35) and studies in ethnically homogeneous populations have reported the enrichment of one of the two sub-phenotypes $(11,19)$. Thus, the higher percentage of the nIHH phenotype in the studied population may reflect a common genetic background among those nIHH patients, which is yet unsurfaced. 


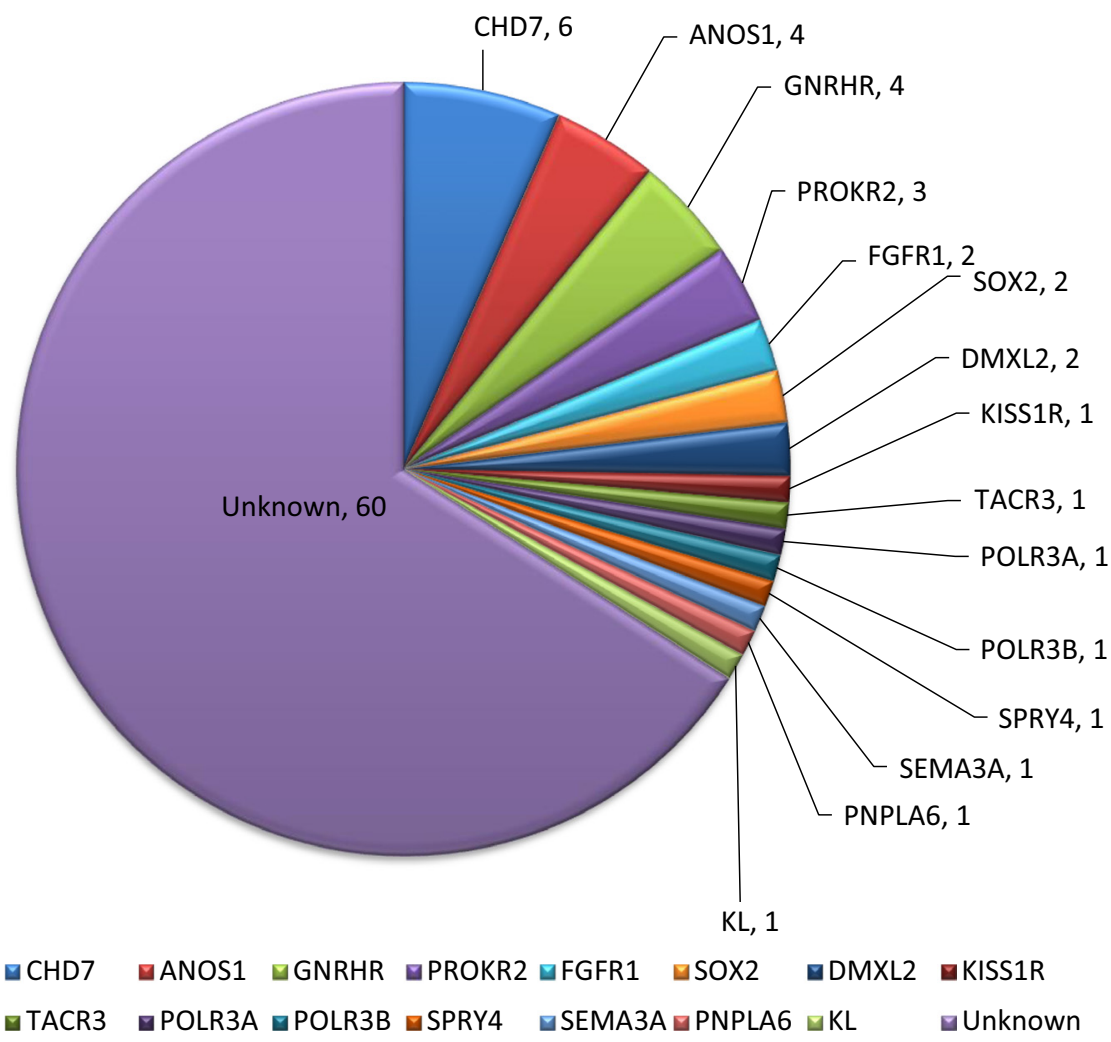

\section{Figure 3}

The genes positive for rare sequence variants (RSVs) detected with whole exome sequencing in 87 IGD patients as well as the number of probands carrying them. RSVs were detected in the following additional genes: DMXL2, SOX2, KL, POLR3A, POLR3B, PNPLA6, SEMA3A and RNF216.
Despite the expansion of the number of probands to 87 , we are still reporting a higher male-to-female ratio in the total number of IGD patients with enrichment for higher male-to-female ratio in KS compared to nIHH patients. The precise reason for the male predominance KS has hitherto been considered to be secondary to the $\mathrm{X}$-linked form of KS. Thus, even though the prevalence of ANOS1 genetic changes was relatively low in the IGD cohort, 4/30 KS patients and 3/ $25 \mathrm{KS}$ males carried a LoF genetic change in ANOS1 including an ANOS1 deletion or nonsense mutation. Additional explanations for this male predominance could be a potential non-genetic cause or possible bias of ascertainment.

In our study, we evaluated the IGD patients for reproductive and non-reproductive symptoms. Patients with or without anosmia displayed a wide spectrum of reproductive phenotypic features, including cryptorchidism and microphallus, with the mean testicular volume of males before initiation of treatment being not different in patients with KS compared to nIHH (data not shown). Importantly, synkinesia and URA were significantly enriched in KS patients and several neuropsychiatric disorders were detected in both KS and nIHH patients, highlighting the importance of detailed clinical evaluation in IGD patients. Even though the genetics of psychiatric disorders is highly complicated $(36,37)$, the outcome of this evaluation along with the previously reported cases of KS and schizophrenia $(38,39)$, raise the importance of such evaluation in patients with IGD and strong family history of neuropsychiatric disorders. The reproductive and non-reproductive data are shown in Table 1.

\section{Genotypic analysis}

Using Sanger sequencing and MLPA we discovered variation in 21 out of 81 IGD patients with a lack of enrichment for a particular genetic cause. Even though a large number of IGD genes were screened, our sample lacked evidence of oligogenicity, i.e. RSVs in more than one gene causing the expression of the phenotype, a phenomenon that has been detected in prior studies affecting $2.5-10 \%$ of the IGD population (data not shown) (34). All these observations could reflect the presence of a yet unidentified genetic cause underlying the Greek cohort of IGD.

Thus, to search for genetic variation in additional IGD genes and determine the prevalence of genetic variation in all genes that have been implicated in the disease, we performed WES, making this the first report of the prevalence of RSVs in a large number of IGD genes (37 genes) using NGS in this population. 
Table 2 The characteristics of the discovered IGD rare sequencing variants.

\begin{tabular}{|c|c|}
\hline Gene & Change \\
\hline CHD7 & $\begin{array}{l}\text { c.8962 8963insG p. } \\
\text { D2988GfsX2 }\end{array}$ \\
\hline CHD7 & c. $5051-4 C>T$ \\
\hline CHD7 & c.1018A>G p.M340V \\
\hline CHD7 & c.7579A >C p.M2527L \\
\hline FGFR1 & c.760C >T p.R254W \\
\hline FGFR1 & c. $1408 \mathrm{C}>\mathrm{T}$ p.R470C \\
\hline SPRY4 & c. $46 \mathrm{G}>\mathrm{A}$ p.V16। \\
\hline GNRHR & c.436C>T p.P146S \\
\hline GNRHR & c $317 A>G$ p Q106R \\
\hline GNRHR & c.785G>A p.R262Q \\
\hline GNRHR & c. $1-8 \mathrm{G}>\mathrm{A}$ \\
\hline KISS1R & c. 458 C $>$ T p.R153C \\
\hline PROKR2 & c. $254 \mathrm{G}>\mathrm{A}$ p.R85H \\
\hline PROKR2 & c.1069C>T p.R357W \\
\hline TACR3 & c.1305T>A p.S435R \\
\hline ANOS1 & $\begin{array}{l}\text { Possible deletion from KAL1 } \\
\text { exon1 through Xp22.31 }\end{array}$ \\
\hline ANOS1 & c.550delC p.L184* \\
\hline ANOS1 & c.1 532C>A p.S511Y \\
\hline$K L$ & c.860G >A p.R287H \\
\hline POLR3A & c.3734G>A p.R1245Q \\
\hline$D M X L 2$ & c.31 04C>G p.P1035R \\
\hline$D M X L 2$ & c. $1787 C>$ G p.S596C \\
\hline PNPLA6 & $\begin{array}{l}\text { c.851 859delinsACCGTGT p. } \\
\text { S284YfsX56 }\end{array}$ \\
\hline$P O L R 3 B$ & c.1958A>T p.D653V \\
\hline POLR3B & c.3358A>G p.M1120V \\
\hline RNF216 & c.1 06G>A p.D36N \\
\hline SPRY4 & c.46G>A p.V16I \\
\hline SOX2 & c. 750 C>A p S250T \\
\hline SOX2 & c. 297 C>A pA99G \\
\hline SEMA3A & c. 1 457C>T p.P486L \\
\hline
\end{tabular}

\begin{tabular}{|c|c|c|}
\hline $\begin{array}{l}\text { Functional } \\
\text { effect }\end{array}$ & PP & Pathogenicity \\
\hline Frameshift & NA & Deleterious \\
\hline Splice site & NA & Deleterious \\
\hline Missense & $0 / 4$ & Benign \\
\hline Missense & $0 / 4$ & Benign \\
\hline Missense & $3 / 4$ & Likely deleterious \\
\hline Missense & $2 / 4$ & Likely deleterious \\
\hline Missense & $1 / 4$ & Likely benign \\
\hline Missense & $3 / 4$ & Likely deleterious \\
\hline Missense & $3 / 4$ & Likely deleterious \\
\hline Missense & $3 / 4$ & Likely deleterious \\
\hline Frameshift & NA & Deleterious \\
\hline Missense & $1 / 4$ & Likely benign \\
\hline Missense & $1 / 4$ & Likely benign \\
\hline Missense & $3 / 4$ & Likely deleterious \\
\hline Missense & $1 / 4$ & Likely benign \\
\hline $\begin{array}{c}\text { Intragenic } \\
\text { deletion }\end{array}$ & NA & Deleterious \\
\hline Nonsense & NA & Deleterious \\
\hline Missense & $0 / 4$ & Benign \\
\hline Missense & $3 / 4$ & Likely deleterious \\
\hline Missense & $0 / 4$ & Benign \\
\hline Missense & $0 / 4$ & Benign \\
\hline Missense & $1 / 4$ & Likely benign \\
\hline Frameshift & NA & Deleterious \\
\hline Missense & $1 / 4$ & Likely benign \\
\hline Missense & $3 / 4$ & Likely deleterious \\
\hline Missense & $2 / 4$ & Likely deleterious \\
\hline Missense & $1 / 4$ & Likely benign \\
\hline Missense & $4 / 4$ & Deleterious \\
\hline Missense & $4 / 4$ & Deleterious \\
\hline Missense & $2 / 4$ & Likely deleterious \\
\hline
\end{tabular}

\begin{tabular}{c}
\hline $\begin{array}{c}\text { MAF in ExAC browse } \\
\text { non-Finnish Europeans }\end{array}$ \\
\hline Not seen \\
Not seen \\
0.0063 \\
0.0031 \\
Not seen \\
0.000015 \\
0.0002462 \\
0.0011 \\
0.003 \\
0.002 \\
Not seen \\
Not seen \\
0.0011 \\
0.00089 \\
0.000029 \\
NA
\end{tabular}

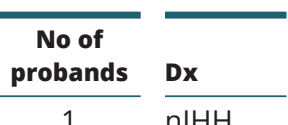

1 nIHH

Not seen
0.0024
0.00001648
0.00283
0.00004946
0.0003747
Not seen

0.006968
0.000008238
Not seen
0.0002822
Not seen
0.000008347
0.00006603

$\begin{array}{ll}1 & \mathrm{KS} \\ 2 & \mathrm{nlHH}, \mathrm{KS} \\ 2 & \mathrm{nIHH} \\ 1 & \mathrm{KS} \\ 1 & \mathrm{nlHH} \\ 1 & \mathrm{KS} \\ 1 & \mathrm{nlHH} \\ 2 & \mathrm{nlHH} \\ 1 & \mathrm{nlHH} \\ 1 & \mathrm{nlHH} \\ 1 & \mathrm{KS} \\ 1 & \mathrm{KS} \\ 1 & \mathrm{nlHH} \\ 1 & \mathrm{nlHH} \\ 2 & \mathrm{KS}\end{array}$

Table 2 shows the characteristics of the detected RSVs including the genomic changes, function effect, number of prediction programs that consider the changes deleterious, pathogenicity, MAF in ExAC, number of probands carrying the diagnosis and associated diagnosis.

WES increased the prevalence of IGD genetic variation to 31 genetic variations in 27 IGD patients and the number of genes implicated in the disease to 15 , suggesting that NGS is crucial for the discovery on genetic variation in patients with such rare diseases. Most importantly, while genetic search in 14 genes did not reveal any oligogenicity, expanding the search to 37 IGD genes detected oligogenicity in 4 cases ( $4 / 87$ probands).

Deleterious, likely deleterious, likely benign and benign genetic variation with multiple inheritance patterns were seen and both single point variations as well as intergenic deletions were detected in 15 genes that affect either the neurodevelopmental and neuroendocrine pathways of IGD including CHD7, ANOS1, FGFR1, PROKR2, GNRHR, DMXL2, SOX2, SPRY4, KISSR1, TACR3, POLR3B, POLR3A, RNF216, SEMA3A and PNAPL6. We discovered several RSVs in neurodevelopmental genes including $\mathrm{CHD} 7$ that was a gene with the most genetic changes, with ANOS1 and PROKR2 following. Apart from the genes that were found to disrupt the neurodevelopmental pathway of IGD, we also detected the variation that affected the genes that form the KNDy neuronal regulatory system that controls GnRH release and action. In fact, GNRHR was the second most prevalence gene carrying RSVs along with ANOS1. GNRHR RSVs were only detected in nIHH patients with a prevalence of 4 out of $57 \mathrm{nIHH}$ patients. All of the RSVs were LoF with 1 of them being slice site and the 3 missense predicted to be deleterious in silico. One more missense TACR3 RSV was detected in $1 \mathrm{nIHH}$ patient and 1 missense KISS1R RSV was detected in a KS patient.

The variety of RSVs that were detected in different IGD genes in this heterogeneous sample of IGD patients of Greek origin is in keeping with the study of a rather mixed population compared to a population isolate

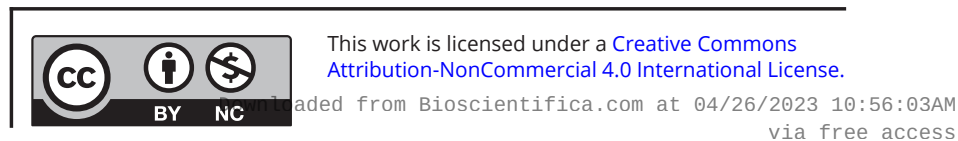


Table 3 In silico validation of the discovered RSVs.

\begin{tabular}{|c|c|c|c|c|c|c|c|}
\hline Gene & Change & $\begin{array}{l}\text { Functional } \\
\text { effect }\end{array}$ & Polyphen & SIFT & Pathner & FАTHMM & ACMG \\
\hline CHD7 & $\begin{array}{l}\text { c.8962_8963insG p.D2988Gfs } \\
\text { het; }\end{array}$ & Frameshift & & & & & Pathogenic \\
\hline CHD7 & c.5051-4C>T het; & Splice site & & Not applicable & & & Benign \\
\hline CHD7 & c.1018A>G p.M340V het; & Missense & Benign & Tolerated & NA & Tolerated & Benign \\
\hline CHD7 & c.7579A>C p.M2527L het; & Missense & Benign & Tolerated & NA & Tolerated & Benign \\
\hline FGFR1 & c.760C >T p.R254W het & Missense & $\begin{array}{l}\text { Probably } \\
\text { damaging }\end{array}$ & Deleterious & Probably damaging & Tolerated & VUS \\
\hline FGFR1 & c.1408C>T p.R470C het; & Missense & Benign & Deleterious & NA & Damaging & VUS \\
\hline GNRHR & c.436C>T p.P146S het; & Missense & $\begin{array}{l}\text { Probably } \\
\text { damaging }\end{array}$ & Deleterious & Probably damaging & Tolerated & VUS \\
\hline$G n R H R$ & c 317A>G p Q106R het & Missense & $\begin{array}{l}\text { Probably } \\
\text { damaging }\end{array}$ & Deleterious & Probably damaging & Tolerated & Pathogenic \\
\hline GNRHR & c.785G >A p.R262Q het; & Missense & $\begin{array}{l}\text { Probably } \\
\text { damaging }\end{array}$ & Deleterious & Probably damaging & Tolerated & Pathogenic \\
\hline GNRHR & c.1-8G>A het; & Frameshift & Not applicable & & & & VUS \\
\hline KISS1R & c.458C > T p.R153C het; & Missense & Benign & Tolerated & Probably damaging & Tolerated & VUS \\
\hline PROKR2 & c.254G>A p.R85H het; & Missense & $\begin{array}{l}\text { Probably } \\
\text { damaging }\end{array}$ & Deleterious & Probably damaging & Tolerated & VUS \\
\hline PROKR2 & c.1069c>T p.R357W het; & Missense & Benign & Tolerated & Probably benign & Tolerated & VUS \\
\hline TACR3 & c.1305T>A p.S435R het; & Missense & Benign & Tolerated & Possible damaging & Tolerated & VUS \\
\hline ANOS1 & c.550delC p.L184* hem & Stop gain & Not applicable & & & & Pathogenic \\
\hline ANOS1 & $\begin{array}{l}\text { possible deletion from KAL1 } \\
\text { exon1 through Xp22.31 }\end{array}$ & $\begin{array}{l}\text { Intragenic } \\
\text { deletion }\end{array}$ & Not applicable & & & & Pathogenic \\
\hline ANOS1 & c.1532C>A p.S511Y het & Missense & Benign & Tolerated & Probably benign & Tolerated & Benign \\
\hline$K L$ & c.860G>A p.R287H het & Missense & $\begin{array}{l}\text { Probably } \\
\text { damaging }\end{array}$ & Deleterious & Probably damaging & Tolerated & VUS \\
\hline POLR3A & c.3734G>A p.R1245Q het; & Missense & Benign & Tolerated & $\mathrm{NA}$ & Tolerated & VUS \\
\hline$D M X L 2$ & c.3104C>G p.P1035R het;; & Missense & Benign & Tolerated & Probably benign & Tolerated & VUS \\
\hline$D M X L 2$ & c.1787C>G p.S596C het; & Missense & Benign & Tolerated & Possible damaging & Tolerated & VUS \\
\hline PNPLA6 & $\begin{array}{l}\text { c.851_859delinsACCGTGT } \\
\text { p.S284YfsX56 het }\end{array}$ & Frameshift & Not applicable & & & & VUS \\
\hline POLR3B & c.1958A>T p.D653V het; & Missense & Benign & Tolerated & Possible damaging & Tolerated & VUS \\
\hline$P O L R 3 B$ & c.3358A>G p.M1120V het; & Missense & $\begin{array}{l}\text { Probably } \\
\text { damaging }\end{array}$ & Deleterious & Possible damaging & Tolerated & VUS \\
\hline RNF216 & c.106G>A p.D36N het; & Missense & $\begin{array}{l}\text { Probably } \\
\text { damaging }\end{array}$ & Tolerated & Possible damaging & Tolerated & VUS \\
\hline SPRY4 & c.46G>A p.V16I het; & Missense & Benign & Tolerated & Possible damaging & Tolerated & VUS \\
\hline SOX2 & c.748T>A p.S250T het & Missense & $\begin{array}{l}\text { Possibly } \\
\text { damaging }\end{array}$ & Deleterious & Possible damaging & Damaging & VUS \\
\hline SOX2 & c. 297 C>A pA99G & Missense & $\begin{array}{l}\text { Possibly } \\
\text { damaging }\end{array}$ & Deleterious & Possible damaging & Damaging & VUS \\
\hline SEMA3A & c.1457C>T p.P486L het; & Missense & $\begin{array}{l}\text { Possibly } \\
\text { damaging }\end{array}$ & Deleterious & Probably benign & Tolerated & VUS \\
\hline
\end{tabular}

Table 3 shows the results of four bioinformatic programs including Polyphen 2, SIFT, Pathner and FATHMM, as well as the assessment based on the ACMG criteria.

VUS, variant of unknown significance.

that is characterized by the presence of distinct founder mutations. The genetic heterogeneity which was observed could also be attributed to the sample selected, since patients came to the clinic from the different parts of Greece. Studies of Greek isolate populations have previously shown an enrichment of genomic loci associated with complex phenotypes such as hematologic traits (40), suggestive of the presence of a common genetic background for such phenotypic characteristics in isolated populations of Greece. Studies in IGD patients from such populations will be crucial for establishing novel genetic causes for other rare and common genetic traits.

Interestingly, despite the enrichment for the normosmic phenotypic variation in our cohort, none of the neuroendocrine genes were found to be significantly enriched in our cohort, in contrast with other IGD subpopulation, highlighting the potential presence of a yet unidentified genetic cause for the disease. 
Additionally, even though the prevalence of genetic variation increased with WES, a large portion of Greek patients with IGD (60 probands) lacked any rare RSVs. The additional lack of genetic explanation of the normosmic phenotypic enrichment suggests that novel genes in coding and/or non-coding regions as well as epigenetic factors could contribute to the expression of the phenotype in that particular subset of patients with IGD.

Future steps in the analysis of the genetic architecture in the Greek cohort of IGD include (i) the analysis of a more homogenous sample of patients with this rare disorder; (ii) the analysis in endogamous familial cases; (iii) analysis in syndromic cases of IGD and finally (iv) search for chromosomal rearrangement with copy number variations that could be carried by such patients. Since WES data are already available in 87 probands and 89 family members search for genetic enrichment in the IGD cohort compared to a control cohort is also likely to lead us to a gene causative for GnRH deficiency in those patients.

This analysis highlights the importance of NGS in the detailed description of the genetic background or rare Mendelian diseases that either appear to be monogenic or oligogenic. It has been striking that to date, traditional gene discovery approaches have yielded a genetic cause in only $\sim 50 \%$ of IGD patients, similar to that described in the IGD Greek cohort (41) while the genetic etiology in the remaining patients is currently unknown. By expanding the genetic screening in the Greek IGD cohort with utilization of WES, we discovered an increase in the prevalence of the RSVs as well as significant detection of oligogenicity. This highlights how genetic defects can be missed due to the limited depth and range of existing sequencing that, to date, has only screened coding sequences or short genome segments with lowresolution techniques. The lack of identification of RSVs in cases with a clear heritable cause of IGD highlights the common notion that genetic changes may still exist in non-coding areas of the human genome, structural defects in the genome or epigenetic factors contributing to the disease.

Limitations of this study include (i) the relatively small sample size of the cohort studied; (ii) the lack of screening for copy number variation in the patients studied and the (iii) lack of availability of all the phenotypic details, especially in the patients referred to the University of Patras.

\section{Supplementary data}

This is linked to the online version of the paper at https://doi.org/10.1530/ EC-19-0010

\section{Declaration of interest}

The authors declare that there is no conflict of interest that could be perceived as prejudicing the impartiality of the research reported.

\section{Funding}

Dr Maria I Stamou would like to thank the Alexander S Onasis Foundation for the support of her research training.

\section{Author contribution statement}

M I S conceived part of the study, participated in its design and coordination, participated in the molecular genetics studies and drafted the manuscript; $\mathrm{P} \vee$ examined the patients, gathered all clinical information and obtained consent from the participants; L P participated in coordination of the project, carried out the molecular genetic studies and participated in the sequence alignment; $\mathrm{K} V$ participated in coordination of the project and carried out part of the molecular genetic studies; G A N conceived of the study, examined most of the patients, obtained informed consent from the subjects and family members and participated in its design and coordination and helped to draft the manuscript. All authors read and approved the final manuscript.

\section{Acknowledgements}

The authors would like to thank Dr William F Crowley for his contribution in the genotyping of the patient in the Reproductive Endocrine Unit of Massachusetts General Hospital and his valuable and constant mentorship. The research was supported by the National Institutes of Health Eunice Kennedy Shriver National Institute of Child Health and Human Development (P50HD028138). They would also like to thank Dr Stephanie Seminara and $\mathrm{Dr}$ Ravikumar Balasubramanian from the Reproductive Endocrine Unit of $\mathrm{MGH}$ and $\mathrm{Dr} \mathrm{K}$ Assimakopoulos for performing the psychiatric evaluation of our patients as well as the following physicians for sharing data of their patients within the cohort they studied: Dr A Dakou-Voutetaki (Athens), Dr A Voutetakis (Athens), Dr Karnaka, Dr A Tsatsoulis (Ioannina), Dr M Andrikoula (Ioanninna), Dr Tsinopoulou-Galli (Thessaloniki), Dr Panidis (Thessaloniki), Dr Papadimas, Dr Goulis (Thessaloniki), Dr Pantsiotou and Dr M Anapliotou (Athens).

\section{References}

1 Stamou MI, Varnavas P, Kentrou M, Adamidou F, Voutetakis A, Jing J, Plummer L, Koika V \& Georgopoulos NA. Isolated GNRH deficiency: genotypic and phenotypic characteristics of the genetically heterogeneous Greek population. European Journal of Endocrinology 2017 176 L1-L5. (https://doi.org/10.1530/EJE-16-0505)

2 Stamou MI, Cox KH \& Crowley WF Jr. Discovering genes essential to the hypothalamic regulation of human reproduction using a human disease model: adjusting to life in the "-Omics" era. Endocrine Reviews 20162016 4-22. (https://doi.org/10.1210/er.2015-1045)

3 Boehm U, Bouloux PM, Dattani MT, de Roux N, Dode C, Dunkel L, Dwyer AA, Giacobini P, Hardelin JP, Juul A, et al. Expert consensus document: European Consensus Statement on congenital hypogonadotropic hypogonadism - pathogenesis, diagnosis and treatment. Nature Reviews: Endocrinology 201511 547-564. (https:// doi.org/10.1038/nrendo.2015.112)

4 Eggers S, Sadedin S, van den Bergen JA, Robevska G, Ohnesorg T, Hewitt J, Lambeth L, Bouty A, Knarston IM, Tan TY, et al. Disorders of sex development: insights from targeted gene sequencing of a large international patient cohort. Genome Biology 201617243. (https://doi.org/10.1186/s13059-016-1105-y)

5 Dong Y, Yi Y, Yao H, Yang Z, Hu H, Liu J, Gao C, Zhang M, Zhou L, Asan, et al. Targeted next-generation sequencing identification of

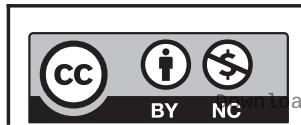

This work is licensed under a Creative Commons Attribution-NonCommercial 4.0 International License. ded from Bioscientifica.com at 04/26/2023 10:56:03AM 
mutations in patients with disorders of sex development. BMC Medical Genetics 201617 23. (https://doi.org/10.1186/s12881-0160286-2)

6 Cassatella D, Howard SR, Acierno JS, Xu C, Papadakis GE, Santoni FA, Dwyer AA, Santini S, Sykiotis GP, Chambion C, et al. Congenital hypogonadotropic hypogonadism and constitutional delay of growth and puberty have distinct genetic architectures. European Journal of Endocrinology $2018 \mathbf{1 7 8} 377$-388. (https://doi.org/10.1530/ EJE-17-0568)

7 Quinton R, Duke VM, Robertson A, Kirk JM, Matfin G, de Zoysa PA, Azcona C, MacColl GS, Jacobs HS, Conway GS, et al. Idiopathic gonadotrophin deficiency: genetic questions addressed through phenotypic characterization. Clinical Endocrinology 200155 163-174. (https://doi.org/10.1046/j.1365-2265.2001.01277.x)

8 Balasubramanian R \& Crowley WF Jr. Isolated GnRH deficiency: a disease model serving as a unique prism into the systems biology of the GnRH neuronal network. Molecular and Cellular Endocrinology 2011346 4-12. (https://doi.org/10.1016/j.mce.2011.07.012)

9 Balasubramanian R, Dwyer A, Seminara SB, Pitteloud N, Kaiser UB \& Crowley WF Jr. Human GnRH deficiency: a unique disease model to unravel the ontogeny of GnRH neurons. Neuroendocrinology 201092 81-99. (https://doi.org/10.1159/000314193)

10 Laitinen EM, Vaaralahti K, Tommiska J, Eklund E, Tervaniemi M, Valanne L \& Raivio T. Incidence, phenotypic features and molecular genetics of Kallmann syndrome in Finland. Orphanet Journal of Rare Diseases 20116 41. (https://doi.org/10.1186/1750-1172-6-41)

11 Sarfati J, Fouveaut C, Leroy C, Jeanpierre M, Hardelin JP \& Dode C. Greater prevalence of PROKR2 mutations in Kallmann syndrome patients from the Maghreb than in European patients. European Journal of Endocrinology 2013169 805-809. (https://doi.org/10.1530/ EJE-13-0419)

12 Tommiska J, Kansakoski J, Christiansen P, Jorgensen N, Lawaetz JG, Juul A \& Raivio T. Genetics of congenital hypogonadotropic hypogonadism in Denmark. European Journal of Medical Genetics 2014 57 345-348. (https://doi.org/10.1016/j.ejmg.2014.04.002)

13 Gu WJ, Zhang Q, Wang YQ, Yang GQ, Hong TP, Zhu DL, Yang JK, Ning G, Jin N, Chen K, et al. Mutation analyses in pedigrees and sporadic cases of ethnic Han Chinese Kallmann syndrome patients. Experimental Biology and Medicine 2015240 1480-1489. (https://doi. org/10.1177/1535370215587531)

14 Seminara SB, Messager S, Chatzidaki EE, Thresher RR, Acierno JS Jr, Shagoury JK, Bo-Abbas Y, Kuohung W, Schwinof KM, Hendrick AG, et al. The GPR54 gene as a regulator of puberty. New England Journal of Medicine 2003349 1614-1627. (https://doi.org/10.1056/ NEJMoa035322)

15 Topaloglu AK, Reimann F, Guclu M, Yalin AS, Kotan LD, Porter KM, Serin A, Mungan NO, Cook JR, Imamoglu S, et al. TAC3 and TACR3 mutations in familial hypogonadotropic hypogonadism reveal a key role for neurokinin B in the central control of reproduction. Nature Genetics 200941 354-358. (https://doi.org/10.1038/ng.306)

16 Topaloglu AK, Tello JA, Kotan LD, Ozbek MN, Yilmaz MB, Erdogan S, Gurbuz F, Temiz F, Millar RP \& Yuksel B. Inactivating KISS1 mutation and hypogonadotropic hypogonadism. New England Journal of Medicine 2012366 629-635. (https://doi.org/10.1056/ NEJMoa1111184)

17 Kotan LD, Hutchins BI, Ozkan Y, Demirel F, Stoner H, Cheng PJ, Esen I, Gurbuz F, Bicakci YK, Mengen E, et al. Mutations in FEZF1 cause Kallmann syndrome. American Journal of Human Genetics 2014 95 326-331. (https://doi.org/10.1016/j.ajhg.2014.08.006)

18 Lim ET, Wurtz P, Havulinna AS, Palta P, Tukiainen T, Rehnstrom K, Esko T, Magi R, Inouye M, Lappalainen T, et al. Distribution and medical impact of loss-of-function variants in the Finnish founder population. PLoS Genetics 201410 e1004494. (https://doi. org/10.1371/journal.pgen.1004494)

19 Gurbuz F, Kotan LD, Mengen E, Siklar Z, Berberoglu M, Dokmetas S, Kilicli MF, Guven A, Kirel B, Saka N, et al. Distribution of gene mutations associated with familial normosmic idiopathic hypogonadotropic hypogonadism. Journal of Clinical Research in Pediatric Endocrinology 20124 121-126. (https://doi.org/10.4274/ jcrpe.725)

20 Spinhoven P, Ormel J, Sloekers PP, Kempen GI, Speckens AE \& Van Hemert AM. A validation study of the Hospital Anxiety and Depression Scale (HADS) in different groups of Dutch subjects. Psychological Medicine 199727 363-370. (https://doi.org/10.1017/ S0033291796004382)

21 Shaw ND, Seminara SB, Welt CK, Au MG, Plummer L, Hughes VA, Dwyer AA, Martin KA, Quinton R, Mericq V, et al. Expanding the phenotype and genotype of female GnRH deficiency. Journal of Clinical Endocrinology and Metabolism 201196 E566-E576. (https:// doi.org/10.1210/jc.2010-2292)

22 Tornberg J, Sykiotis GP, Keefe K, Plummer L, Hoang X, Hall JE, Quinton R, Seminara SB, Hughes V, Van Vliet G, et al. Heparan sulfate 6-O-sulfotransferase 1 , a gene involved in extracellular sugar modifications, is mutated in patients with idiopathic hypogonadotrophic hypogonadism. PNAS 2011108 11524-11529. (https://doi.org/10.1073/pnas.1102284108)

23 MacArthur DG, Manolio TA, Dimmock DP, Rehm HL, Shendure J, Abecasis GR, Adams DR, Altman RB, Antonarakis SE, Ashley EA, et al. Guidelines for investigating causality of sequence variants in human disease. Nature 2014508 469-476. (https://doi.org/10.1038/ nature13127)

24 Samocha KE, Robinson EB, Sanders SJ, Stevens C, Sabo A, McGrath LM, Kosmicki JA, Rehnstrom K, Mallick S, Kirby A, et al. A framework for the interpretation of de novo mutation in human disease. Nature Genetics 201446 944-950. (https://doi.org/10.1038/ ng.3050)

25 de Roux N, Young J, Misrahi M, Genet R, Chanson P, Schaison G \& Milgrom E. A family with hypogonadotropic hypogonadism and mutations in the gonadotropin-releasing hormone receptor. New England Journal of Medicine 1997337 1597-1602. (https://doi. org/10.1056/NEJM199711273372205)

26 Caron P, Chauvin S, Christin-Maitre S, Bennet A, Lahlou N, Counis R, Bouchard P \& Kottler ML. Resistance of hypogonadic patients with mutated GnRH receptor genes to pulsatile GnRH administration. Journal of Clinical Endocrinology and Metabolism 1999 84 990-996. (https://doi.org/10.1210/jcem.84.3.5518)

27 Koika V, Varnavas P, Valavani H, Sidis Y, Plummer L, Dwyer A, Quinton R, Kanaka-Gantenbein C, Pitteloud N, Sertedaki A, et al. Comparative functional analysis of two fibroblast growth factor receptor 1 (FGFR1) mutations affecting the same residue (R254W and R254Q) in isolated hypogonadotropic hypogonadism (IHH). Gene 2013516 146-151. (https://doi.org/10.1016/j. gene.2012.12.041)

28 Adzhubei IA, Schmidt S, Peshkin L, Ramensky VE, Gerasimova A, Bork P, Kondrashov AS \& Sunyaev SR. A method and server for predicting damaging missense mutations. Nature Methods 20107 248-249. (https://doi.org/10.1038/nmeth0410-248)

29 Kumar P, Henikoff S \& Ng PC. Predicting the effects of coding nonsynonymous variants on protein function using the SIFT algorithm. Nature Protocols 20094 1073-1081. (https://doi.org/10.1038/ nprot.2009.86)

30 Shihab HA, Gough J, Cooper DN, Stenson PD, Barker GL, Edwards KJ Day IN \& Gaunt TR. Predicting the functional, molecular, and phenotypic consequences of amino acid substitutions using hidden Markov models. Human Mutation 201334 57-65. (https://doi. org/10.1002/humu.22225)

31 Richards S, Aziz N, Bale S, Bick D, Das S, Gastier-Foster J, Grody WW, Hegde M, Lyon E, Spector E, et al. Standards and guidelines for the interpretation of sequence variants: a joint consensus recommendation of the American College of Medical Genetics and Genomics and the Association for Molecular Pathology. Genetics in Medicine 201517 405-424. (https://doi.org/10.1038/gim.2015.30) 
32 Costa-Barbosa FA, Balasubramanian R, Keefe KW, Shaw ND, Al-Tassan N, Plummer L, Dwyer AA, Buck CL, Choi JH, Seminara SB, et al. Prioritizing genetic testing in patients with Kallmann syndrome using clinical phenotypes. Journal of Clinical Endocrinology and Metabolism 201398 E943-E953. (https://doi.org/10.1210/jc.2012-4116)

33 Georgopoulos NA, Koika V, Galli-Tsinopoulou A, Spiliotis BE, Adonakis G, Keramida MK, Sgourou A, Koufogiannis KD, Papachatzopoulou A, Papavassiliou AG, et al. Renal dysgenesis and KAL1 gene defects in patients with sporadic Kallmann syndrome. Fertility and Sterility 200788 1311-1317. (https://doi.org/10.1016/j. fertnstert.2006.12.044)

34 Sykiotis GP, Plummer L, Hughes VA, Au M, Durrani S, NayakYoung S, Dwyer AA, Quinton R, Hall JE, Gusella JF, et al. Oligogenic basis of isolated gonadotropin-releasing hormone deficiency. PNAS 2010107 15140-15144. (https://doi.org/10.1073/pnas.1009622107)

35 Pitteloud N, Hayes FJ, Boepple PA, DeCruz S, Seminara SB, MacLaughlin DT \& Crowley WF Jr. The role of prior pubertal development, biochemical markers of testicular maturation, and genetics in elucidating the phenotypic heterogeneity of idiopathic hypogonadotropic hypogonadism. Journal of Clinical Endocrinology and Metabolism 200287 152-160. (https://doi.org/10.1210/ jcem.87.1.8131)

36 Ripke S, O’Dushlaine C, Chambert K, Moran JL, Kahler AK, Akterin S, Bergen SE, Collins AL, Crowley JJ, Fromer M, et al. Genome-wide association analysis identifies 13 new risk loci for schizophrenia.
Nature Genetics 201345 1150-1159. (https://doi.org/10.1038/ ng.2742)

37 Lee SH, DeCandia TR, Ripke S, Yang J, Sullivan PF, Goddard ME, Keller MC, Visscher PM \& Wray NR. Estimating the proportion of variation in susceptibility to schizophrenia captured by common SNPs. Nature Genetics 201244 247-250. (https://doi.org/10.1038/ ng.1108)

38 Vagenakis GA, Hyphantis TN, Papageorgiou C, Protonatariou A, Sgourou A, Dimopoulos PA, Mavreas V, Vagenakis AG \& Georgopoulos NA. Kallmann's syndrome and schizophrenia. International Journal of Psychiatry in Medicine 200434 379-390. (https://doi.org/10.2190/HXR5-DGRC-JCMQ-0CBH)

39 Verhoeven WM, Egger JI, Hovens JE \& Hoefsloot L. Kallmann syndrome and paranoid schizophrenia: a rare combination. BMJ Case Reports 20132013 bcr2012007387. (https://doi.org/10.1136/bcr2012-007387)

40 Panoutsopoulou K, Hatzikotoulas K, Xifara DK, Colonna V, Farmaki AE, Ritchie GR, Southam L, Gilly A, Tachmazidou I, Fatumo S, et al. Genetic characterization of Greek population isolates reveals strong genetic drift at missense and trait-associated variants. Nature Communications 20145 5345. (https://doi.org/10.1038/ ncomms6345)

41 Crowley WF Jr. Commentary: the year in endocrine genetics for basic scientists. Molecular Endocrinology 201125 1989-2002. (https://doi. org/10.1210/me.2011-1247)

Received in final form 24 March 2019

Accepted 28 March 2019

Accepted Preprint published online 28 March 2019
This work is licensed under a Creative Commons Attribution-NonCommercial 4.0 International License. ded from Bioscientifica.com at 04/26/2023 10:56:03AM 